\title{
An explanatory factor analysis on procurement risk and its multi-dimensional consequences
}

\author{
Shara Aghajanian $^{\mathrm{a}^{*}}$ and Seyed Mohsen SeyedAliAkbar ${ }^{\mathrm{b}}$
}

${ }^{a}$ Master student, School of Industrial Engineering, South Tehran Branch, Islamic Azad University, Tehran, Iran

${ }^{b}$ Assistant Professor, School of Industrial Engineering, South Tehran Branch, Islamic Azad University, Tehran, Iran

\section{H R O N I C L E}

Article history:

Received March 15, 2014

Received in revised format 28 July 2014

Accepted August 292014

Available online

September 72014

Keywords:

Procurement risk analysis

Supply chain management

Explanatory factor analysis

Delphi method \begin{abstract}
A B S T R A C T
Procurement risks analysis is a crucial study in supply chain risk management. According to the phenomenon of snow ball effect, if a risk occurs at the primitive node between buyer and supplier, it will be strengthened and extended throughout the entire network. Hence, it can have more disruptive influences comparing with risks that happen in further nodes. In this paper, through a case study, the most important risk factors and its multi-dimensional consequences in procurement risk analysis is derived from the literature review and implementing a Delphi method that takes into account the nine risks factors and 39 preliminary variables as risk consequences. The nine risk factors are limits of global communication, packaging and transportation, procedures and standards, sanction, supply of equipment, price of equipment, Communication, management of technology and delivery mistakes.
\end{abstract}

(C) 2015 Growing Science Ltd. All rights reserved.

\section{Introduction}

In today's supply chain networks, one of the main goals is to integrate all nodes and activities in order to get the most efficient flow. In every node of this network there are lots of risks that are potentially affecting the supply chain networks by imposing lots of cost, delays and as a result the integrity at the whole network will be destroyed. The Supply Chain Risk Management (SCRM) especially procurement risk management is one of the most important issues in Supply Chain Management (SCM) cause if a risk that is usually multi-dimensional, by the concept of having multiple consequences, occurs at primitive node between buyer and supplier it will be proliferated and amplified throughout the entire supply chain network and therefore, it reveals the phenomenon of the "snowball effect" (Świerczek, 2013). By knowing the importance of the buyer-supplier risks including procurement risks, many risks are identified and assessed in this node. (Ellram et al., 2002; Goh, Lim, \& Meng, 2007; Zsidisin et al., 2005) defines supply risk as the potential occurrence of an incident associated with the inbound supply from individual supplier failures or the supply market in which its outcomes would result in the inability of the purchasing firm to meet demand or threaten customer well-being and safety. External risks, on the other hand, arise from the interactions between the supply chain network and its environment, such as international terrorism, and natural disasters

* Corresponding author

E-mail address: shara.aghajanian@yahoo.com (S. Aghajanian) 
like SARS. In the supplier choosing activity, the supplier that doesn't have the capability of meeting requirements for quantity, quality and delivery will have a consequences like production delays, poor quality products, unfilled orders, lost customers, Loss of market share (Smeltzer \& Siferd, 1998).

Technology is one the main factors that influenced the increasing (decreasing) of the risks, (Kim \& Chavas, 2003) suggests that technological change can also generate benefits by reducing the farmers' exposure to production risk. In the purchasing process there isn't any doubt about the importance of information technology, many researchers have studied the usage of information technology to improve the buyer-supplier relationships (Carr \& Smeltzer, 2002; Ellram \& Zsidisin, 2002), or they try to analyze the e-procurement and technological changes benefits (Trkman \& McCormack, 2010). The result is showing that the technology and management of technology are playing a significant role in mitigating the risk of buyer-supplier relationships by increasing the trust, decreasing the cost and the lead time.

Transportation risk is one of the risks that happens between buyer-supplier, international transportation activities are growing in a very fast pace and the concept of transportation safety has been migrated from the traditional "non-accident announce" to risk management (Yang et al., 2005). Risk management in supplier networks aims to illustrate challenges that network operation brings to risk management and when the dependency between companies increases, they become more exposed to the risks of other companies, hence the buyer-supplier communication is a considerable factor in procurement risk analysis (Hallikas et al., 2004). Supply chain risks can be managed more effectively by applying the SCRM Process. The structured approach can be divided into the phases of risk identification, risk measurement, risk assessment; risk evaluation, risk mitigation contingency plans; risk control and monitoring via data management systems (Tummala \& Schoenherr, 2011). A key process involved in supply chains is a priori evaluation of potential partners, not only in terms of expected cost, but also in terms of product failure risk, producing company failure risk, and even political risk (Olson \& Wu, 2011). In partnership of buyers and suppliers, researchers have worked on supplier side risks; they enhance the perception of investment in decision-making, and also they investigate risks in buyer-dominating supplier networks (Ojala \& Hallikas, 2006). Pipelines have proven to be one of the cheapest ways to transport hydrogen However; failures in pipelines can pose major risks. According to the severity and the location of incident, the multi-dimensional consequences will be fatality, non-lethal human damages, monetary unit, impact area and diversity impact (Lins \& de Almeida, 2012). Multi-dimensional perspective is used in relation to the Supplier and buyer partnership by focusing on three supplier management practices, namely the strategic longterm relationship, supplier assessment, and logistics integration. They test their effects on four operations performance, including quality, delivery, flexibility and cost (Prajogo et al., 2012).

\section{The proposed study}

Several review papers and theoretical frameworks are investigated to achieve a comprehensive list of nine procurement risk factors (Baloi \& Price, 2003; Harland et al., 2003; Humphrey, 2003; Kim \& Chavas, 2003; Trkman \& McCormack, 2010; Yang et al., 2005), since there is a limited data on procurement risk factors and especially for its multi-dimensional consequences, a Delphi method is proposed by choosing five experts to attain the procurement risk factors and its multi-dimensional consequences. The Delphi method has proven to be an efficient survey method when only a limited amount of data on a topic is available (Linstone \& Turoff, 2011; Rowe, Wright, \& Bolger, 1991). The major goal of the technique is to assistant structure the group communication processes so that the process is effective in allowing individuals to deal with complex problems (Linstone \& Turoff, 2011). We derive nine risks factors and 39 consequences as initial variables from reviewing the literature and implementing the Delphi method.

The proposed study of this paper investigates the impact of important factors on the procurement risk in a supply chain risk management. The proposed study designs a questionnaire consists of 33 
questions in 10-point scale questionnaire. We have used Cronbach alpha to verify the reliability of the questionnaire and it yielded 0.896, which is well above the minimum desirable level of 0.70 . The Skewness, multi-collinearity, measure of sampling adequacy (MSA) was tested and by principal component analysis (PCA) and also varimax rotation using SPSS 20 the independent factors are derived. Skewness wasn't a problem and according to the nature of the Consequences of the risks, we expected to have some multi-collinearity in the data analysis, four variables were omitted through this analysis and two variables were omitted in MSA process, so the 39 initial variables comes into 33 final variable for implementing the Explanatory Factor Analysis.

\section{The results}

In this section, we present details of our survey on factor analysis. According to the factor weights in every table, all of the consequences are sorted by the most important factors weight to the least important one.

\subsection{Limits of global communication}

The first variable of the factor analysis is associated with limits of global communication related to the procurement risk in supply chain network. This factor includes five variables including inability to compete, backwardness of technology, loss of market sharing, raising the total cost and to have communicate with suppliers by lower credit. Cronbach alpha has been calculated as $78.5 \%$ and Table 1 shows details of our findings.

\section{Table 1}

Factor analysis for procurement limits of global communication risk and its multi-dimensional consequences

\begin{tabular}{|c|c|c|c|c|}
\hline Option/variables & Sorted Factor Weight & Eigen value & $\%$ of variance & Accumulated \\
\hline Inability to compete & 0.744 & \multirow{5}{*}{8.924} & \multirow{5}{*}{27.042} & \multirow{5}{*}{27.042} \\
\hline Backwardness of technology & 0.738 & & & \\
\hline Loss of market sharing & 0.624 & & & \\
\hline raising the total Cost & 0.615 & & & \\
\hline To have communicate with suppliers by lower credit & 0.498 & & & \\
\hline
\end{tabular}

\subsection{Packaging and transportation}

The second variable of the factor analysis is associated with packing and transportation related to the procurement risk in supply chain network. This factor includes four variables including damage to goods during the transportations, loss of time to replace the damaged goods, challenge between buyers-suppliers and carriers, and re-working to fix mistakes. Cronbach alpha has been calculated as $85.3 \%$ and Table 2 shows details of our findings.

\section{Table 2}

Details of factor analysis for procurement packaging and transportation risk and its multi-dimensional consequences Option/variables

Damage to goods during the Transportations Sorted Factor Weight 0.839

Loss of time to replace the damaged goods $\quad 0.746$

Challenge between buyers-suppliers and carriers $\quad 0.693$

Re-working to fix mistakes Eigen value $\%$ of variance Accumulated

\subsection{Procedures and Standards}

The third variable of the factor analysis is associated with procedures and standards related to the procurement risk in supply chain network.

\section{Table 3}

Details of factor analysis for procurement procedures and standards risk and its multi-dimensional consequences

\begin{tabular}{|c|c|c|c|c|}
\hline Option/variables & Sorted Factor Weight & Eigen value & $\%$ of variance & Accumulated \\
\hline Rising the total cost & 0.756 & \multirow{4}{*}{2.576} & \multirow{4}{*}{7.809} & \multirow{4}{*}{43.536} \\
\hline Lack of coordination and careful planning to implement projects & 0.67 & & & \\
\hline Get lower equipment's and services & 0.61 & & & \\
\hline $\begin{array}{l}\text { Imposing excessive administrative bureaucracy to replace the } \\
\text { materials or fixing the problem }\end{array}$ & 0.53 & & & \\
\hline
\end{tabular}


This factor includes four variables including rising the total cost, lack of coordination and careful planning to implement projects, get lower equipment's and services, and imposing excessive administrative bureaucracy to replace the materials or fixing the problem. Cronbach alpha has been calculated as $73.5 \%$ and Table 3 shows details of our findings.

\subsection{Sanction}

The fourth variable of the factor analysis is associated with sanction related to the procurement risk in supply chain network. This factor includes three variables including payment complexity from the corresponding channels, transportation and delivery problems, and imposing unreasonable conditions to the buyer. Cronbach alpha has been calculated as $72.8 \%$ and Table 4 shows details of our findings.

\section{Table 4}

Details of factor analysis for procurement sanction risk and its multi-dimensional consequences

\begin{tabular}{lcccc}
\hline Option/variables & Sorted Factor Weight & Eigen value & \% of variance & Accumulated \\
\hline Payment complexity from the corresponding channels. & 0.867 & \multirow{2}{*}{0} & \multirow{2}{*}{49.065} \\
Transportation and delivery problems & 0.808 & 0.68 & & \\
Imposing unreasonable conditions to the buyer & & & \\
\hline
\end{tabular}

\subsection{Supply of equipment}

The fifth variable of the factor analysis is associated with the supply of equipment related to the procurement risk in supply chain network. This factor includes three variables including reduction in company revenue, customer dissatisfaction, and inability to compete. Cronbach alpha has been calculated as $77.4 \%$ and Table 5 shows details of our findings.

\section{Table 5}

Details of factor analysis for procurement supply of equipment risk and its multi-dimensional consequences

\begin{tabular}{|c|c|c|c|c|}
\hline Option/variables & Sorted Factor Weight & Eigen value & $\%$ of variance & Accumulated \\
\hline Reduction in company revenue & 0.862 & \multirow{3}{*}{1.730} & \multirow{3}{*}{5.252} & \multirow{3}{*}{54.307} \\
\hline Customer dissatisfaction & 0.760 & & & \\
\hline Inability to compete & 0.736 & & & \\
\hline
\end{tabular}

\subsection{Price of equipment}

The sixth variable of the factor analysis is associated with the price of equipment related to the procurement risk in supply chain network. This factor includes four variables including raising the cost of buying equipment, raising the price for the customers, delay or destruction of the projects, and to have communicate with limited number of suppliers. Cronbach alpha has been calculated as $71.6 \%$ and Table 6 shows details of our findings.

\section{Table 6}

Details of factor analysis for procurement price of equipment risk and its multi-dimensional consequences

\begin{tabular}{|c|c|c|c|c|}
\hline Option/variables & Factor Weight & Eigen value & $\%$ of variance & Accumulated \\
\hline Raising the cost of buying equipment & 0.745 & \multirow{4}{*}{1.563} & \multirow{4}{*}{4.736} & \multirow{4}{*}{59.043} \\
\hline Raising the Price for the customers & 0.600 & & & \\
\hline Delay or destruction of the Projects & 0.591 & & & \\
\hline To have communicate with Limited number of suppliers & 0.560 & & & \\
\hline
\end{tabular}

\subsection{Communication}

The seventh variable of the factor analysis is associated with the communication related to the procurement risk in supply chain network. This factor includes three variables including achieving the goods under global quality standards, an obligation to have communicate with suppliers by lower credit and lack of network quality. Cronbach alpha has been calculated as $68.4 \%$ and Table 7 shows details of our findings. 
Table 7

Details of factor analysis for procurement communication risk and its multi-dimensional consequences

\begin{tabular}{|c|c|c|c|c|}
\hline Option/variables & Sorted Factor Weight & Eigen value & $\%$ of variance & Accumulated \\
\hline Achieving the goods under global quality standards & 0.815 & \multirow{3}{*}{1.355} & \multirow{3}{*}{4.108} & \multirow{3}{*}{63.151} \\
\hline $\begin{array}{l}\text { An obligation to have communicate with suppliers by } \\
\text { lower credit }\end{array}$ & 0.796 & & & \\
\hline Lack of network quality & 0.469 & & & \\
\hline
\end{tabular}

\subsection{Delivery mistakes}

The eighth variable of the factor analysis is associated with the delivery mistakes related to the procurement risk in supply chain network. This factor includes four variables including technical problems in the network due to the incompatibility of purchased equipment, inability to compete, delays in project implementation (due to quality mistake) and delays in project implementation (due to quantity mistake). Cronbach alpha has been calculated as $70.4 \%$ and Table 8 shows details of our findings.

\section{Table 8}

Details of factor analysis for procurement delivery mistakes risk and its multi-dimensional consequences

\begin{tabular}{|c|c|c|c|c|}
\hline Option/variables & Sorted Factor Weight & Eigen value & $\%$ of variance & Accumulated \\
\hline $\begin{array}{l}\text { Technical problems in the network due to the } \\
\text { incompatibility of purchased equipment }\end{array}$ & 0.579 & \multirow{4}{*}{1.077} & \multirow{4}{*}{3.265} & \multirow{4}{*}{66.416} \\
\hline Inability to compete & 0.521 & & & \\
\hline Delays in project implementation (due to quality mistake) & 0.491 & & & \\
\hline Delays in project implementation (due to quantity mistake) & 0.439 & & & \\
\hline
\end{tabular}

\subsection{Management of technology}

The ninth variable of the factor analysis is associated with the management of technology related to the procurement risk in supply chain network. This factor includes three variables including inability to compete, fail to benefit from the value-added services and customer dissatisfaction. Cronbach alpha has been calculated as $60.5 \%$ and Table 9 shows details of our findings.

\section{Table 9}

Details of factor analysis for procurement management of technology risk and its multi-dimensional consequences

\begin{tabular}{|c|c|c|c|c|}
\hline Option/variables & Sorted Factor Weight & Eigen value & $\%$ of variance & Accumulated \\
\hline Inability to compete & 0.767 & \multirow{3}{*}{1.043} & \multirow{3}{*}{3.162} & \multirow{3}{*}{69.576} \\
\hline Fail to benefit from the value-added services & 0.441 & & & \\
\hline Customer dissatisfaction & 0.446 & & & \\
\hline
\end{tabular}

\section{Conclusion}

This study sought to present the important factors that influences the procurement risk in supply chain network by deriving the risks and its multi-dimensional consequences. We help the decision makers to have a better insight about the risk severity by deriving the multi-dimensional consequences and the result show that our study covered the 69.576 percentage of the overall variance for the included factors in the study. Hence, we may not allow concluding that unmeasured latent variables aren't existed in the model. But at least we could show that our research is covering the most effective factors for the model of procurement risk and its multi-dimensional consequences. The included nine factors are limits of global communication, packaging and transportation, procedures and standards, sanction, supply of equipment, price of equipment, communication, management of technology and delivery mistakes and the most important consequences of every risk are shown in every table by its sorted factor weight. For the future research as we believe that buyer-supplier risks have snow-ball effects, therefore it can have more disruptive effects comparing with risks that happen in subsequent nodes; so many researches are needed to make the buyer-supplier risk (factors) and its consequences (variables) more comprehensive and in addition confirmatory factor analysis is needed to confirm this 
model. In predictive risk management before using risk management strategy, for finding the detailed causes of every risk root cause methodology can be used so beside of having the multi-dimensional consequences by root causing the risks we can have a risks and its multi-dimensional causes model in order to enhance the buyer-supplier risks perception more clearly and also to provide a better model for helping the decision makers.

\section{References}

Baloi, D., \& Price, A. D. (2003). Modelling global risk factors affecting construction cost performance. International Journal of Project Management, 21(4), 261-269.

Carr, A. S., \& Smeltzer, L. R. (2002). The relationship between information technology use and buyer-supplier relationships: an exploratory analysis of the buying firm's perspective. Engineering Management, IEEE Transactions on, 49(3), 293-304.

Ellram, L. M., \& Zsidisin, G. (2002). Factors that drive purchasing and supply management's use of information technology. Engineering Management, IEEE Transactions on, 49(3), 269-281.

Ellram, L. M., Zsidisin, G. A., Siferd, S. P., \& Stanly, M. J. (2002). The impact of purchasing and supply management activities on corporate success. Journal of Supply Chain Management, 38(4), 4-17.

Goh, M., Lim, J., \& Meng, F. (2007). A stochastic model for risk management in global supply chain networks. European Journal of Operational Research, 182(1), 164-173.

Hallikas, J., Karvonen, I., Pulkkinen, U., Virolainen, V.-M., \& Tuominen, M. (2004). Risk management processes in supplier networks. International Journal of Production Economics, 90(1), 47-58.

Harland, C., Brenchley, R., \& Walker, H. (2003). Risk in supply networks. Journal of Purchasing and Supply management, 9(2), 51-62.

Humphrey, J. (2003). Globalization and supply chain networks: the auto industry in Brazil and India. Global Networks, 3(2), 121-141.

Kim, K., \& Chavas, J. P. (2003). Technological change and risk management: an application to the economics of corn production. Agricultural economics, 29(2), 125-142.

Lins, P., \& de Almeida, A. (2012). Multidimensional risk analysis of hydrogen pipelines. International Journal of Hydrogen Energy, 37(18), 13545-13554.

Linstone, H. A., \& Turoff, M. (2011). Delphi: a brief look backward and forward. Technological Forecasting and Social Change, 78(9), 1712-1719.

Ojala, M., \& Hallikas, J. (2006). Investment decision-making in supplier networks: Management of risk. International Journal of Production Economics, 104(1), 201-213.

Olson, D. L., \& Wu, D. (2011). Risk management models for supply chain: a scenario analysis of outsourcing to China. Supply Chain Management: An International Journal, 16(6), 401-408.

Prajogo, D., Chowdhury, M., Yeung, A. C., \& Cheng, T. (2012). The relationship between supplier management and firm's operational performance: a multi-dimensional perspective. International Journal of Production Economics, 136(1), 123-130.

Rowe, G., Wright, G., \& Bolger, F. (1991). Delphi: a reevaluation of research and theory. Technological Forecasting and Social Change, 39(3), 235-251.

Smeltzer, L. R., \& Siferd, S. P. (1998). Proactive supply management: the management of risk. International Journal of Purchasing and Materials Management, 34(4), 38-45.

Swierczek, A. (2013). The impact of supply chain integration on the "snowball effect" in the transmission of disruptions: An empirical evaluation of the model. International Journal of Production Economics.

Trkman, P., \& McCormack, K. (2010). Estimating the benefits and risks of implementing e-procurement. Engineering Management, IEEE Transactions on, 57(2), 338-349.

Tummala, R., \& Schoenherr, T. (2011). Assessing and managing risks using the supply chain risk management process (SCRMP). Supply Chain Management: An International Journal, 16(6), 474-483.

Yang, Y.-L., Shyu, W.-H., Lin, C.-H., \& Hsu, S.-F. (2005). Risk management of international transportation of integrated circuit products. Journal of the Eastern Asia Society for Transportation Studies, 6, 3386-3400.

Zsidisin, G. A., Melnyk, S. A., \& Ragatz, G. L. (2005). An institutional theory perspective of business continuity planning for purchasing and supply management. International journal of production research, 43(16), 3401-3420. 